\title{
Construction of anion-functionalized hypercrosslinked ionic porous polymers for efficient separation of bioactive molecules
}

\author{
Xian Suo ${ }^{\dagger}$, Yuqi Huang ${ }^{\dagger}$, Zhenkang Li, Hanqian Pan, Xili Cui and Huabin Xing*
}

\begin{abstract}
Porous ionic polymers have demonstrated great potential for high-performance separation by the merits of their unique molecular recognition, but the preparation of anion-functionalized ionic polymers for the separation of bioactive molecules with highly similar structures remains a challenge. Here, through the facile Friedel-Crafts alkylation between benzylimidazole ionic liquids (ILs) and crosslinkers, several anion-functionalized hypercrosslinked ionic porous polymers (HIPs) are reported, which are well decorated with strongly basic carboxylate anions as well as feature tubular morphology and excellent thermal stability. High adsorption capacity (103.6 $\mathrm{mg} \mathrm{g}^{-1}$ for tocopherol homologues) and selectivity $\left(S_{\beta \& \gamma / \alpha}, 4.26 ; S_{\delta / \alpha}, 3.19\right)$ for bioactive compounds with high structural similarity have been realized, superior to those of commercial adsorbents, hypercrosslinked polymer without ILs, and HIPs with common ILs. This study manifests a new synthetic strategy and rational molecular design for functionalized adsorbents, as well as offers new opportunities to enable high-performance separation.
\end{abstract}

Keywords: anion-functionalization, hypercrosslink, porous ionic polymers, adsorption, tocopherol homologues, phenolic compounds

\section{INTRODUCTION}

Porous organic polymers, benefiting from their structural diversity, extremely high porosity, and physicochemical stability, have emerged as a versatile platform for practical applications [1-6]. Precise control of pore structure and pore chemistry promotes the deployment of advanced separation [7-13]. Taskspecific functional site is a key factor to enhance the separation efficiency. However, the additional chemical groups decorated onto the pore wall often restrict pore accessibility and lack flexible variability. The utilization of dynamic ionic pairs could weaken the steric-hindrance obstacle and endow the adsorbents with selective interactions with adsorbates [14]. By the merits of unique nanoporous ionic environment, high-performance applications have been developed [14-17]. The past decade has witnessed rapid progress in multiple synthetic methods towards porous ionic polymers [18-21]. The post-modification method provides a facile pathway to introduce ionic sites but suffers from decreased porosity [18]. Templated synthetic strategies afford well-defined architecture, but inevitably sacrifice templates and rarely construct micropores [19,20]. Hypercrosslinked polymers (HCPs) represent a class of nanoporous materials, featuring extremely high surface areas as well as high chemical and thermal stability, which offer practical and potential applications in the fields of gas sorption and separation, catalysis, and drug delivery [22-26]. Recently, a class of hypercrosslinked ionic porous polymers (HIPs), combining the properties of porous polymers and ionic materials, have been reported, which incorporate ionic liquid (IL)-like ionic sites into the architecture [18,27-31]. With a few exciting recent exceptions, benzylimidazole ILs, in which the imidazolium cation is linked by methylene with phenyl ring, have been employed, the synthesized HIPs afford abundant meso-microporosity and adjustable IL contents [27,30,31].

The rational choice of anions makes for broadened applications [10,32]. Recently, our group reported a kind of mesoporous poly(ionic liquid)s, with long-chain carboxylate ILs, which exhibited a high adsorption capacity of bioactive tocopherol homologues and excellent selectivity [33]. However, the existing HIPs have been almost derived from common ILs with bromine $\left(\mathrm{Br}^{-}\right)$or chlorine $\left(\mathrm{Cl}^{-}\right)$anions. Typically, the facile incorporation of functional anions was achieved via anion exchange but troubled by the steric hindrance especially for bulky anions. And the research of HIPs was mainly focused on selective carbon dioxide capture and heterogeneous catalysis but has been rarely explored for the separation of bioactive compounds. Therefore, the construction of anion-functionalized HIPs for high-performance separation is of great potential but still challenging.

Herein, we prepared several new anion-functionalized HIPs endowed with carboxylate ILs featuring strong hydrogenbonding basicity and great biocompatibility, via a direct FriedelCrafts alkylation reaction between the benzylimidazole IL monomers and crosslinkers. These prepared anion-functionalized HIPs exhibit abundant meso-microporosity and tunable IL contents, as well as feature tubular morphology and excellent thermal stability. For bioactive tocopherol homologues and phenolic compounds with highly similar structures, high-performance adsorptive separation has been achieved by the anionfunctionalized HIPs, in comparison to commercial adsorbents, HCP without ILs, and HIPs with common ILs. And recycling tests for the adsorption tocopherol homologues verify the good reusability for anion-functionalized HIPs.

Key Laboratory of Biomass Chemical Engineering of Ministry of Education, College of Chemical and Biological Engineering, Zhejiang University, Hangzhou 310027, China

${ }^{\dagger}$ These authors contributed equally to this work.

* Corresponding author (email: xinghb@zju.edu.cn) 


\section{EXPERIMENTAL SECTION}

\section{Synthesis of 1-benzyl-3-methylimidazolium-based ILs}

The ILs synthesized in this work were 1-benzyl-3-methylimidazolium bromide ([BzMIm][Br]), 1-benzyl-3-methylimidazolium acetate ([BzMIm] $\left.\left[\mathrm{CH}_{3} \mathrm{COO}\right]\right)$, 1-benzyl-3-methylimidazolium caproate ([BzMIm] $\left.\left[\mathrm{C}_{5} \mathrm{H}_{11} \mathrm{COO}\right]\right)$ and 1-benzyl-3methylimidazolium laurate ([BzMIm] $\left[\mathrm{C}_{11} \mathrm{H}_{23} \mathrm{COO}\right]$ ) (Fig. S1). As shown in Fig. S2, [BzMIm] [Br] was prepared by the quaterisation reaction of equimolar 1-methylimidazole and benzyl bromide in ethanol at $333 \mathrm{~K}$ for $24 \mathrm{~h}$. For the preparation of [BzMIm] $\left[\mathrm{CH}_{3} \mathrm{COO}\right],[\mathrm{BzMIm}]\left[\mathrm{C}_{5} \mathrm{H}_{11} \mathrm{COO}\right]$, and [BzMIm]$\left[\mathrm{C}_{11} \mathrm{H}_{23} \mathrm{COO}\right], \quad$ [BzMIm] $[\mathrm{Br}]$ aqueous solution was passed through a strongly basic anion-exchange resin (Dowex Monosphere 550A UPW; OH type) to get [BzMIm] $[\mathrm{OH}]$ and then mixed with equimolar amounts of the corresponding fatty acids including acetic acid, $n$-hexanoic acid and lauric acid at room temperature for $24 \mathrm{~h}$ [34-37]. All the obtained ILs were dried by a vacuum freeze dryer for $24 \mathrm{~h}$ after most solvents were removed by a rotary evaporator at $333 \mathrm{~K}$. The chemical structure and purity of ILs were evaluated by a ${ }^{1} \mathrm{H}$ nuclear magnetic resonance (NMR) spectrum (see the Supplementary information).

\section{Synthesis of IL-based HCPs}

Several IL-based HCPs were synthesized via the Friedel-Crafts alkylation reaction with the ratio of ILs: $\alpha, \alpha^{\prime}$-dibromo- $p$-xylene (DBX):ferric chloride $\left(\mathrm{FeCl}_{3}\right)=1: 2: 4$ (mol:mol:mol). The reaction was carried out with $\mathrm{FeCl}_{3}$ as a catalyst and 1,2-dichloroethane (DCE) as a solvent in nitrogen atmosphere at $353 \mathrm{~K}$ for $24 \mathrm{~h}$. Afterwards, the solid products were filtered and washed with ethanol and water until the solution became colorless. Then the filtered solid products were dried in a vacuum oven at $333 \mathrm{~K}$ for $24 \mathrm{~h}$. The obtained HCPs were named HIP-[BzMIm] [Br], HIP-[BzMIm] $\left[\mathrm{CH}_{3} \mathrm{COO}\right]$, HIP-[BzMIm] $\left[\mathrm{C}_{5} \mathrm{H}_{11} \mathrm{COO}\right]$ and HIP[BzMIm] $\left[\mathrm{C}_{11} \mathrm{H}_{23} \mathrm{COO}\right]$. For comparison, $\mathrm{HCP}$ without ILs was also prepared only using DBX, following a similar procedure.

\section{Batch adsorption experiments}

The batch adsorption experiments were implemented as follows. For tocopherol homologues, $20 \mathrm{~mL}$ of $n$-heptane solution was prepared with $1.41 \mathrm{mg} \mathrm{mL}^{-1} \alpha$-tocopherol, $1.40 \mathrm{mg} \mathrm{mL}^{-1} \beta$ - and $\gamma$-tocopherol and $0.56 \mathrm{mg} \mathrm{mL}^{-1} \delta$-tocopherol in a conical flask. For organic phenolic compounds, the $n$-heptane solution contained $1.06 \mathrm{mg} \mathrm{mL}^{-1}$ phenol, $1.13 \mathrm{mg} \mathrm{mL}^{-1} p$-cresol and $1.22 \mathrm{mg} \mathrm{mL}^{-1}$ 2,6-dimethylphenol. Then HCPs $(0.1 \mathrm{~g})$ were added and shaken at $160 \mathrm{rmin}^{-1}$ and $298 \mathrm{~K}$ for $24 \mathrm{~h}$. After achieving adsorption equilibrium, the filtered solution was analyzed by high-performance liquid chromatography (HPLC). The detailed analytical condition of HPLC and calculation can be seen in the Supplementary information.

Furthermore, batch adsorption experiments using $2.3 \mathrm{~g}$ of HIP-[BzMIm] $\left[\mathrm{C}_{5} \mathrm{H}_{11} \mathrm{COO}\right]$ were also carried out to evaluate practical separation performance. After achieving adsorption equilibrium, the filtered solution was analyzed using HPLC. The adsorbent was regenerated, and adsorbed tocopherols were collected with ethanol at $45^{\circ} \mathrm{C}$. The corresponding results were summarized in Table S1.

\section{RESULTS AND DISCUSSION}

Fig. 1 displays the synthetic route for anion-functionalized HIPs. Imidazolium cation featuring phenyl group has been chosen to participate in the Friedel-Crafts reaction with the crosslinker DBX in the presence of $\mathrm{FeCl}_{3}$ and DCE as the catalyst and solvent, respectively. The formed methylene bridges between the crosslinker and benzene ring in ILs can hypercrosslink ionic sites into the polymer skeleton. Meanwhile, the methylene bridges between the crosslinkers can further promote the construction of porous ionic network. The rational selection for the kinds of anions and adequate IL contents possesses the potential to accomplish high-performance separation for organic compounds with highly similar structures.

\section{Synthesis and characterization of HIPs}

In this work, several anion-functionalized HIPs derived from carboxylate ILs were successfully fabricated. For exploring the effect of carbon number of carboxylate anions, $[\mathrm{BzMIm}]\left[\mathrm{CH}_{3^{-}}\right.$ $\mathrm{COO}],[\mathrm{BzMIm}]\left[\mathrm{C}_{5} \mathrm{H}_{11} \mathrm{COO}\right]$ and $[\mathrm{BzMIm}]\left[\mathrm{C}_{11} \mathrm{H}_{23} \mathrm{COO}\right]$ with different carboxylate anions were employed to construct hypercrosslinked networks, respectively. The molar ratio of ILs and the crosslinker DBX was chosen to be 2:1 for further study. Their chemical compositions were detected by element analysis, which verifies the successful introduction of carboxylate ILs, and

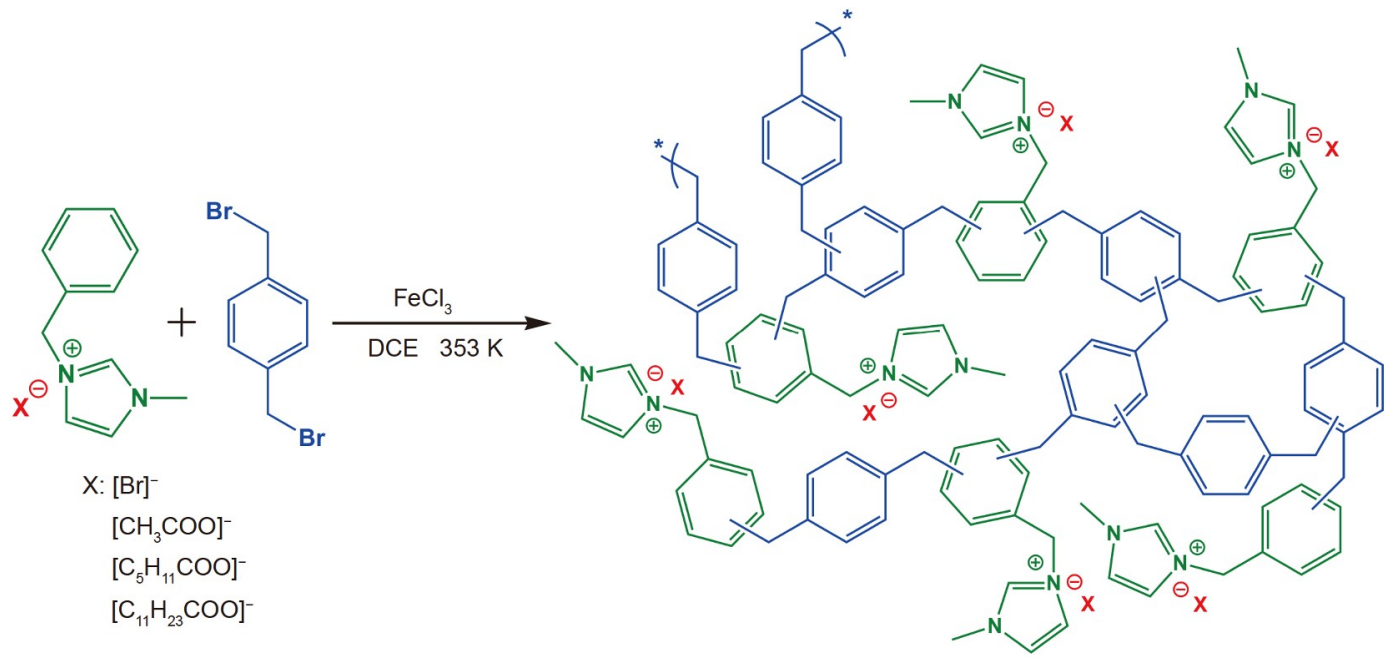

Figure 1 Synthesis route of HIPs by Friedel-Crafts alkylation. 
the calculated contents of ILs in HIPs range from 0.44 to $0.81 \mathrm{mmol} \mathrm{g}^{-1}$. To investigate the pore structure of the HIPs, the $\mathrm{N}_{2}$ adsorption/desorption isotherms were collected at $77 \mathrm{~K}$. The detailed textural parameters were summarized in Table 1, Fig. 2 and Fig. S3. As depicted in Fig. 2, anion-functionalized HIPs show typical type I isotherms with a faint type IV character. The isotherms exhibit a rapid uptake at a low relative pressure, reflecting all the samples demonstrate abundant microporosities with micropore sizes mainly ranging from 0.59 to $2.00 \mathrm{~nm}$. And there is a slightly increased uptake at high relative pressures $\left(P / P_{0}>0.9\right)$, indicating of the coexistence of micropores and a small number of mesopores. In contrast to others, HIP-[BzMIm] $\left[\mathrm{C}_{5} \mathrm{H}_{11} \mathrm{COO}\right]$ derived from ILs with a medium carbon number of carboxylate anions affords the highest IL content of $0.81 \mathrm{mmol} \mathrm{g}^{-1}$, the surface area (calculated by Brunauer-Emmett-Teller (BET) equation, referred as $S_{\mathrm{BET}}$ ) is $323 \mathrm{~m}^{2} \mathrm{~g}^{-1}$, the total pore volume $\left(V_{\text {total }}\right)$ is $0.281 \mathrm{~cm}^{3} \mathrm{~g}^{-1}$, and the mesopore size $\left(D_{\mathrm{BJH}}\right)$ is $5.36 \mathrm{~nm}$; for microporosity $(<2 \mathrm{~nm})$, the micropore surface area $\left(S_{\text {micro }}\right)$ is $149 \mathrm{~m}^{2} \mathrm{~g}^{-1}$, and pore volume ( $V_{\text {micro }}$ ) is $0.075 \mathrm{~cm}^{3} \mathrm{~g}^{-1}$, affording $26.7 \%$ of $V_{\text {total }}$ value, the median micropore size $\left(D_{\mathrm{HK}}\right)$ is $0.51 \mathrm{~nm}$. HIP-[BzMIm]$\left[\mathrm{CH}_{3} \mathrm{COO}\right]$ and HIP-[BzMIm] $\left[\mathrm{C}_{11} \mathrm{H}_{23} \mathrm{COO}\right]$ with lower IL contents of 0.55 and $0.44 \mathrm{mmol} \mathrm{g}^{-1}$ exhibit more abundant microporosity, higher $S_{\mathrm{BET}}\left(512\right.$ and $\left.516 \mathrm{~m}^{2} \mathrm{~g}^{-1}\right)$ and $V_{\text {total }}(0.328$

Table 1 Textural parameters of HCPs

\begin{tabular}{|c|c|c|c|c|c|c|c|c|c|}
\hline Sample & $\begin{array}{c}S_{\mathrm{BET}}{ }^{\mathrm{a}} \\
\left(\mathrm{m}^{2} \mathrm{~g}^{-1}\right)\end{array}$ & $\begin{array}{c}S_{\text {micro }} \mathbf{b} \\
\left(\mathrm{m}^{2} \mathrm{~g}^{-1}\right)\end{array}$ & $\begin{array}{c}V_{\text {micro }}{ }^{\mathbf{b}} \\
\left(\mathrm{cm}^{3} \mathrm{~g}^{-1}\right)\end{array}$ & $\begin{array}{c}V_{\text {total }}{ }^{\mathrm{c}} \\
\left(\mathrm{cm}^{3} \mathrm{~g}^{-1}\right)\end{array}$ & $\begin{array}{c}V_{\text {micro }} / V_{\text {total }} \\
(\%)\end{array}$ & $V_{\text {mso }} / V_{\text {micro }}$ & $D_{\mathrm{DJH}}{ }^{\mathbf{d}}(\mathrm{nm})$ & $D_{\mathrm{HK}}{ }^{\mathrm{e}}(\mathrm{nm})$ & $\begin{array}{l}\text { IL content } \\
\left(\mathrm{mmol} \mathrm{g}^{-1}\right)\end{array}$ \\
\hline $\mathrm{HCP}$ & 843 & 436 & 0.224 & 0.730 & 30.7 & 2.26 & 5.92 & 0.48 & 0 \\
\hline HIP-[BzMIm] $[\mathrm{Br}]$ & 494 & 354 & 0.181 & 0.302 & 59.9 & 0.67 & 4.06 & 0.44 & 0.43 \\
\hline HIP-[BzMIm] $\left[\mathrm{CH}_{3} \mathrm{COO}\right]$ & 512 & 359 & 0.183 & 0.328 & 55.8 & 0.79 & 4.51 & 0.45 & 0.55 \\
\hline HIP-[BzMIm] $]\left[\mathrm{C}_{5} \mathrm{H}_{11} \mathrm{COO}\right]$ & 323 & 149 & 0.075 & 0.281 & 26.7 & 2.75 & 5.36 & 0.51 & 0.81 \\
\hline HIP-[BzMIm] $\left[\mathrm{C}_{11} \mathrm{H}_{23} \mathrm{COO}\right]$ & 516 & 362 & 0.185 & 0.340 & 54.4 & 0.84 & 4.85 & 0.44 & 0.44 \\
\hline HIP-[BzMIm] $\left[\mathrm{C}_{5} \mathrm{H}_{11} \mathrm{COO}\right](1: 4)^{\mathbf{g}}$ & 855 & 390 & 0.168 & 1.151 & 14.6 & 5.85 & 10.7 & 0.52 & 0.40 \\
\hline HIP-[BzMIm] $\left[\mathrm{C}_{5} \mathrm{H}_{11} \mathrm{COO}\right](1: 1)^{\mathrm{g}}$ & 65 & 47 & 0.021 & 0.035 & 60.0 & 0.67 & 5.71 & 0.60 & 1.02 \\
\hline
\end{tabular}

a) BET surface area evaluated from $\mathrm{N}_{2}$ adsorption isotherms at relative pressures $\left(P / P_{0}\right)$ from 0.05 to 0.30 . b) Micropore surface area and volume estimated by the t-plot method. c) Total pore volume at $P / P_{0}=0.990$. d) Average mesopore size calculated by $\mathrm{BJH}$ adsorption equation for $P / P_{0}$ from 0.1 to 0.990 . e) Median micropore size calculated using Horvath-Kawazoe (HK) equation for $P / P_{0}$ from 0.1 to the lowest value. $\mathrm{f}$ ) The IL contents on the HIPs determined from the element analysis. g) HIP-[BzMIm] $\left[\mathrm{C}_{5} \mathrm{H}_{11} \mathrm{COO}\right]$ prepared by the reaction of IL with DBX at ratios of $1: 1$ and 1:4, respectively; others prepared by the reaction of ILs with DBX at the ratios of 1:2.
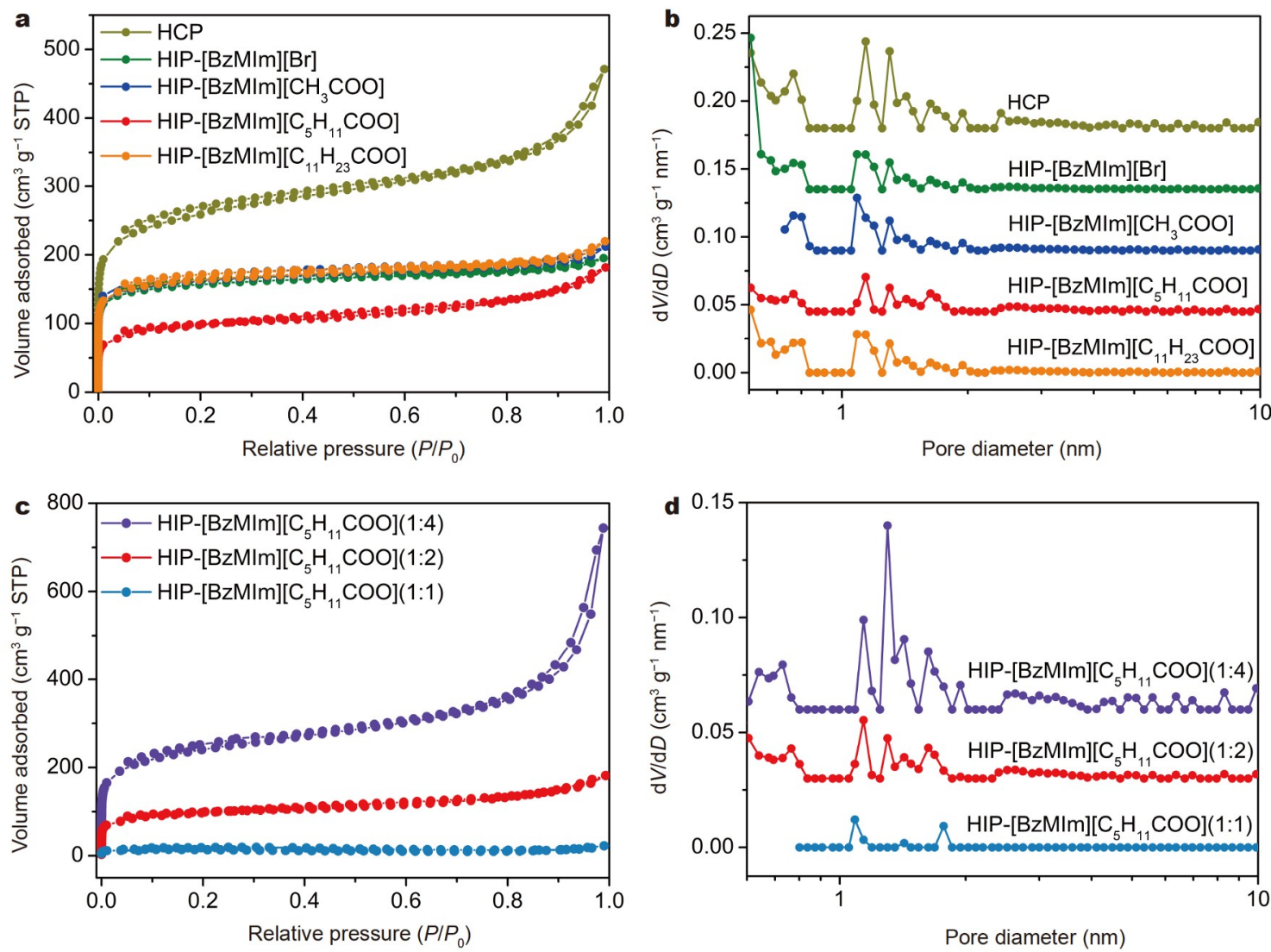

Figure $2 \mathrm{~N}_{2}$ adsorption/desorption isotherms (a, c) and pore size distributions (b, d) of HCPs. 
and $0.340 \mathrm{~cm}^{3} \mathrm{~g}^{-1}$ ), as well as higher $S_{\text {micro }}\left(359\right.$ and $362 \mathrm{~m}^{2} \mathrm{~g}^{-1}$ ) and $V_{\text {micro }}\left(0.183\right.$ and $0.185 \mathrm{~cm}^{3} \mathrm{~g}^{-1}$, accounting for $55.8 \%$ and $54.4 \%$ of $V_{\text {total }}$ value), the $D_{\mathrm{BJH}}$ values are 4.51 and $4.85 \mathrm{~nm}$, respectively, the $D_{\mathrm{HK}}$ values are 0.45 and $0.44 \mathrm{~nm}$, respectively. HIP-[BzMIm][Br], with the IL content of $0.43 \mathrm{mmol} \mathrm{g}^{-1}$, exhibits similar textural parameters with HIP-[BzMIm] $\left[\mathrm{CH}_{3} \mathrm{COO}\right]$ and HIP-[BzMIm] $\left[\mathrm{C}_{11} \mathrm{H}_{23} \mathrm{COO}\right]$. Its $S_{\mathrm{BET}}$ and $V_{\text {total }}$ values reach $494 \mathrm{~m}^{2} \mathrm{~g}^{-1}$ and $0.302 \mathrm{~cm}^{3} \mathrm{~g}^{-1}$. According to the above results, it can be concluded that the carbon number of carboxylate anions and the kind of anions have few effects on the pore structure, whereas the IL content in HIPs is the key factor, which will be further explored in detail. Besides, the pure crosslinker DBX was polymerized for comparison, and the resultant polymer is denoted as HCP, which also displays a type I and type IV mixed isotherm along with the highest surface area and pore volume $\left(S_{\text {BET }}: 843 \mathrm{~m}^{2} \mathrm{~g}^{-1}, V_{\text {total }}: 0.730 \mathrm{~cm}^{3} \mathrm{~g}^{-1}\right)$.

To explore the effect of IL content on the pore structure, HIPs with $[\mathrm{BzMIm}]\left[\mathrm{C}_{5} \mathrm{H}_{11} \mathrm{COO}\right]$ were synthesized with different ratios of ILs and DBX including 1:1, 1:2 and 1:4. The content of ILs in the resulted polymer increases with the increased initial ratio of IL to crosslinker. Because of the easy self-aggregation of IL moiety, the higher IL content, the lower surface area and pore volume. As depicted in Fig. 2c, d, the three HIPs present remarkably different $\mathrm{N}_{2}$ sorption isotherms. HIP-[BzMIm][ $\left.\mathrm{C}_{5} \mathrm{H}_{11} \mathrm{COO}\right]$ (1:4) (1:4 denotes the molar ratio of ILs and DBX) with the lowest IL content of $0.40 \mathrm{mmol} \mathrm{g}^{-1}$ presents a sharper and higher uptake at a low $P / P_{0}(<0.03)$ than others, indicative of more abundant microporosity. Meanwhile, it displays an increased uptake at $P / P_{0}$ ranging from 0.4 to 0.8 and a sharp rise at high $P / P_{0}(>0.8)$, implying the existence of mesopores and macropores (Fig. 2d). Its $S_{\mathrm{BET}}$ and $V_{\text {total }}$ values are up to $855 \mathrm{~m}^{2} \mathrm{~g}^{-1}$ and $1.151 \mathrm{~cm}^{3} \mathrm{~g}^{-1}$. In a striking contrast, HIP[BzMIm] $\left[\mathrm{C}_{5} \mathrm{H}_{11} \mathrm{COO}\right]$ (1:1) possesses the highest IL content of
$1.02 \mathrm{mmol} \mathrm{g}^{-1}$, while its $S_{\mathrm{BET}}$ and $V_{\text {total }}$ values are low to $65 \mathrm{~m}^{2} \mathrm{~g}^{-1}$ and $0.035 \mathrm{~cm}^{3} \mathrm{~g}^{-1}$. These results manifest that excessive IL content could make the materials non-porous. Proper molar ratio of ILs and DBX can achieve the "trade-off" for the ionic nature and pore structure, which is important for adsorptive separation application.

The morphological structure is worth investigating for further applications. The scanning electron microscopy (SEM) and transmission electron microscopy (TEM) images indicate that HIPs and HCP possess different morphologies on the micrometer level (Fig. 3a, d, Figs S4 and S5). HCP exhibits an amorphous morphology composed of irregular particles. HIP$[\mathrm{BzMIm}][\mathrm{Br}]$ presents aggregations of large particles. Differently, HIP-[BzMIm] $\left[\mathrm{C}_{5} \mathrm{H}_{11} \mathrm{COO}\right]$ exists mainly as nanotubes with a mean exterior diameter of $200 \mathrm{~nm}$, which is also displayed in the TEM images. The tubular morphology is probably attributed to the self-assembly behavior of carboxylate ILs in the polymerization process. For $\mathrm{HIP}-[\mathrm{BzMIm}]\left[\mathrm{C}_{5} \mathrm{H}_{11} \mathrm{COO}\right](1: 1)$ with a higher IL content, the hollow nanotubes present a larger mean exterior diameter of $1.92 \mu \mathrm{m}$. Such well-developed structure promotes substrate diffusion and adsorption, as well as provides new ideas for the design and synthesis of ionic porous adsorbents. Rational design of the tubular HIPs could also provide new opportunities of porous nanotube materials with promising application [38-41]. XRD patterns of HCP and HIP[BzMIm] $\left[\mathrm{C}_{5} \mathrm{H}_{11} \mathrm{COO}\right]$ show that these polymers all possess amorphous structure (Fig. S6). Moreover, Fourier transform infrared (FTIR) spectroscopy was collected to identify the chemical composition (Fig. 3c). Compared with HCP, the absorption peaks of HIPs at $1150 \mathrm{~cm}^{-1}$ are assigned to substituted N3 in imidazolium-based ILs, the peaks ranging from 1570 to $1670 \mathrm{~cm}^{-1}$ represent the characteristic peaks of the imidazole ring skeleton [33]. As shown in Fig. S7, the solid a
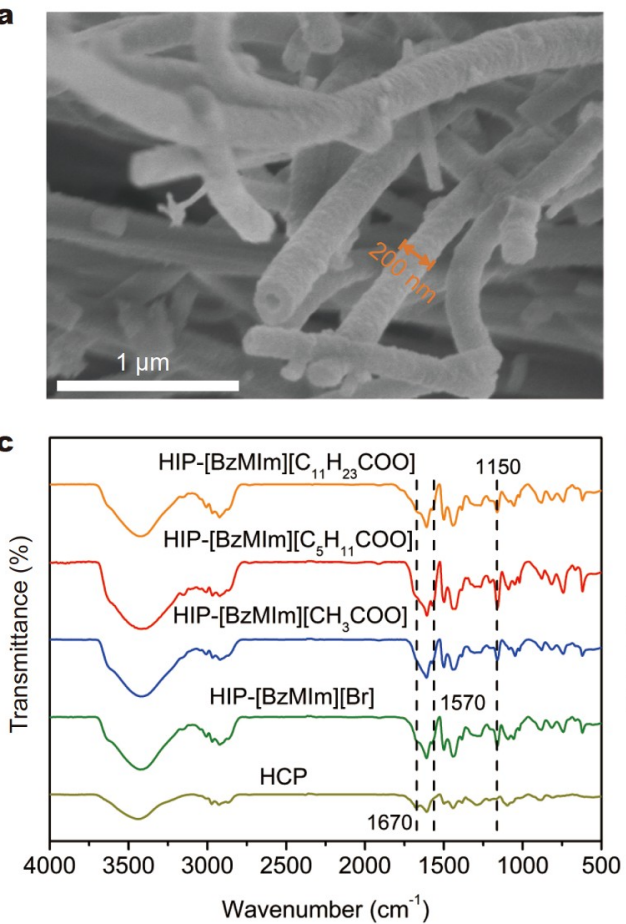
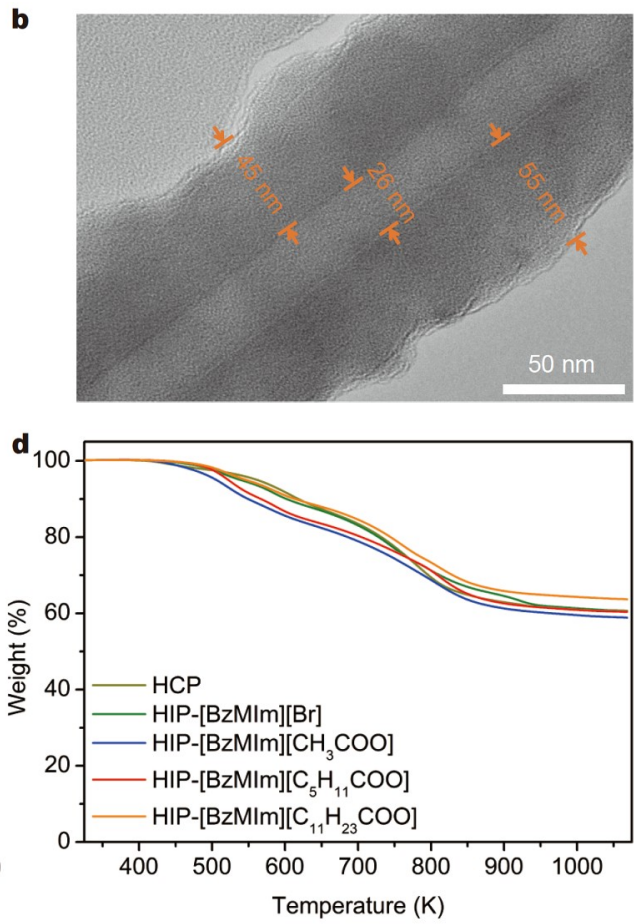

Figure 3 SEM image (a) and TEM image (b) of HIP-[BzMIm] $\left[\mathrm{C}_{5} \mathrm{H}_{11} \mathrm{COO}\right]$; the comparison of FTIR (c) and TGA curves (d) at $\mathrm{N}_{2}$ atmosphere for HIPs and HCP. 
state ${ }^{13} \mathrm{C}$ NMR spectrum also provides evidence for the successful introduction of IL moiety. The thermogravimetric analysis (TGA) results indicate that HIPs afford excellent thermal stability-the temperature for $10 \%$ weight loss under the $\mathrm{N}_{2}$ atmosphere is higher than $550 \mathrm{~K}$ (Fig. 3d), which is beneficial to practical applications.

\section{Selective separation of tocopherol homologues}

The efficient purification of bioactive compounds is the key step to achieve their high value. Tocopherols are the main compositions of natural vitamin $\mathrm{E}$, and their antioxidative capacity makes tocopherols be free radical scavengers and important for human health and food supplement industry $[42,43]$. Among the tocopherol homologues, $\alpha$-tocopherol possesses the highest biological activity, but always coexisting with $\beta-, \gamma$-, and $\delta$ tocopherols. These tocopherol homologues possess high structural similarity, all of which contain a chromanol head and an alkyl side chain with slight differences in the number and position of methyl groups on the chromanol head (Fig. S8) [44]. Therefore, the separation of $\alpha$-tocopherol is of great significance but challenging. The difference in their hydrogen-bonding acidities, which decrease as $\delta$-tocopherol $>\beta$ - and $\gamma$-tocopherol $>\alpha$-tocopherol, provides the possibility for the selective separation of $\alpha$-tocopherol from the homologues $[45,46]$. Many progresses on ILs and deep eutectic solvents (DESs) capable of achieving efficient separation of tocopherols have been made, but there are still difficulties in the subsequent separation pro- cess, which requires much energy consumption [37,47-53]. It is necessary to design high-efficiency adsorbents to improve this difficult purification process.

In this work, anion-functionalized HIPs, with dual characteristics of porous polymers and carboxylate ILs, afford efficient adsorptive separation of tocopherol homologues. The batch experiments with tocopherols were executed to explore the separation performance for the HCPs. As shown in Fig. 4a, all the anion-functionalized HIPs (HIP-[BzMIm] $\left[\mathrm{C}_{n} \mathrm{H}_{2 n+1} \mathrm{COO}\right], n$ $=1,5,11)$ demonstrate high tocopherol adsorption capacities (95.5-109.5 $\mathrm{mg} \mathrm{g}^{-1}$ ). HIP-[BzMIm] $\left[\mathrm{CH}_{3} \mathrm{COO}\right]$ possesses the highest tocopherol adsorption capacity reaching $109.5 \mathrm{mg} \mathrm{g}^{-1}$ at $25^{\circ} \mathrm{C}$, which is significantly higher than that of HIP-[BzMIm][Br] with common anion $\mathrm{Br}^{-}$and similar structure parameters $\left(83.2 \mathrm{mg} \mathrm{g}^{-1}\right)$. HCP without ILs affords the highest specific surface area and total pore volume $\left(S_{\mathrm{BET}}: 843 \mathrm{~m}^{2} \mathrm{~g}^{-1}, V_{\text {total }}\right.$ : $\left.0.730 \mathrm{~cm}^{3} \mathrm{~g}^{-1}\right)$, as well as accounts for higher $V_{\text {micro }} / V_{\text {total }}(30.7 \%)$ than that of better-performing HIP-[BzMIm] $\left[\mathrm{C}_{5} \mathrm{H}_{11} \mathrm{COO}\right]$ $\left(103.6 \mathrm{mg} \mathrm{g}^{-1}\right.$ for tocopherols, $S_{\text {BET }}: 323 \mathrm{~m}^{2} \mathrm{~g}^{-1}, \quad V_{\text {total }}$ : $\left.0.281 \mathrm{~cm}^{3} \mathrm{~g}^{-1}, V_{\text {micro }} / V_{\text {total }}: 26.7 \%\right)$, but the lowest tocopherol adsorption capacity $\left(68.8 \mathrm{mg} \mathrm{g}^{-1}\right)$. It can be explained that the introduction of ionic sites is the key factor for enhancing the separation performance: ILs and tocopherols serve as hydrogenbonding receptors and donors, respectively; IL moieties being embedded in the highly crosslinked network can improve the adsorption capacity by hydrogen-bonding interaction between ILs and tocopherols; and more strongly basic carboxylate ILs
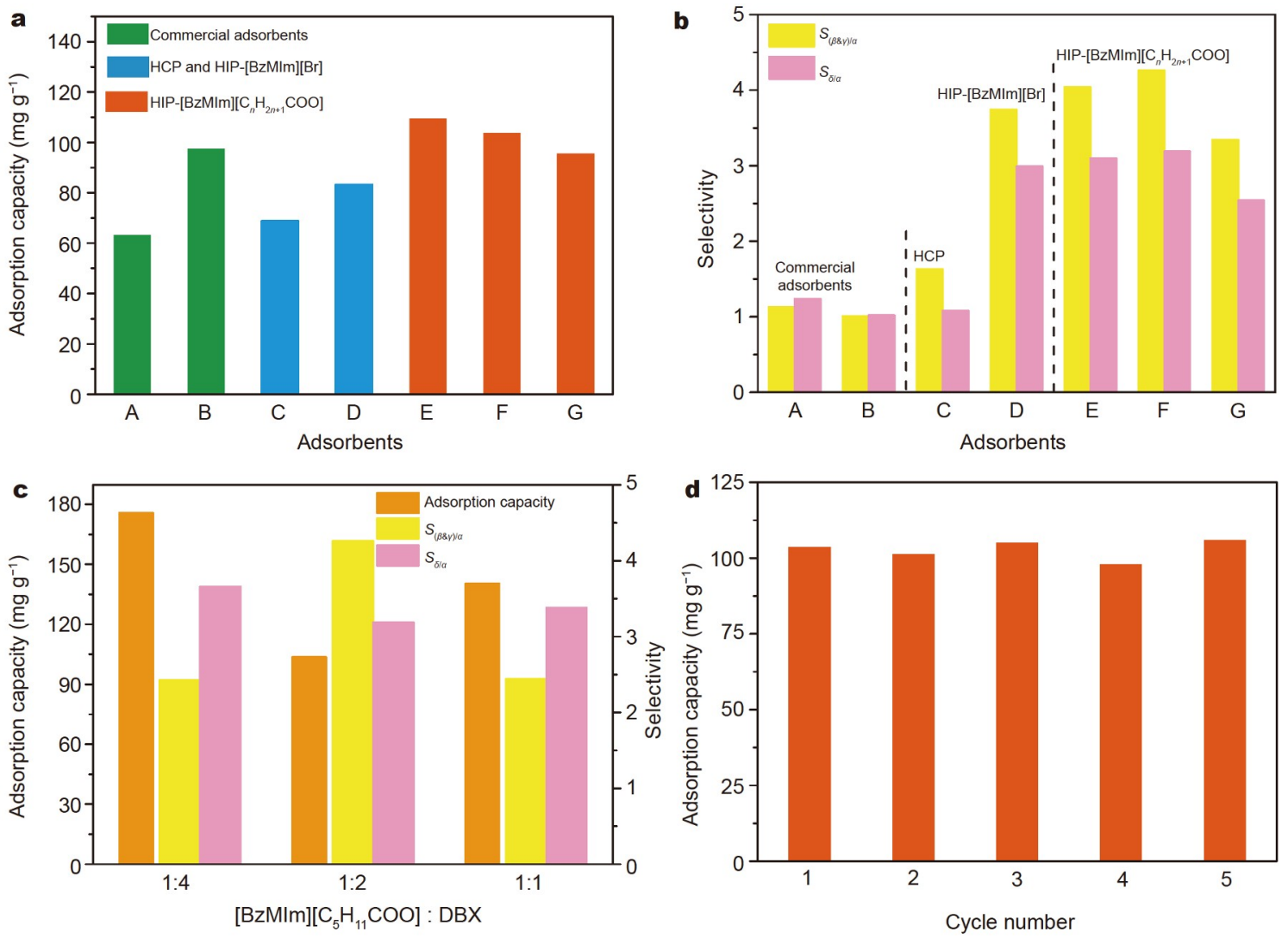

Figure 4 Adsorption capacity (a) and selectivity (b) of tocopherol homologues by different adsorbents at $298 \mathrm{~K}$. Adsorbents: A, Amberlite XAD-4;

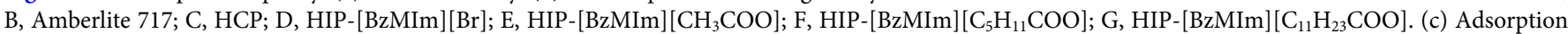
capacity and selectivity of tocopherol homologues by HIP-[BzMIm] $\left[\mathrm{C}_{5} \mathrm{H}_{11} \mathrm{COO}\right]$ with different IL contents at $298 \mathrm{~K}$. (d) Five cycles of tocopherol homologues adsorption for HIP-[BzMIm] $\left[\mathrm{C}_{5} \mathrm{H}_{11} \mathrm{COO}\right]$ at $298 \mathrm{~K}$. 
have a more pronounced effect on the enhanced adsorption of tocopherols than common anions [34,38,52-55]. Besides, the tocopherol adsorption capacity of HIP-[BzMIm] $\left[\mathrm{CH}_{3} \mathrm{COO}\right]$ surpasses those of commercial resins including Amberlite XAD$4\left(63.2 \mathrm{mg} \mathrm{g}^{-1}\right)$ and Amberlite 717 (97.5 $\left.\mathrm{mg} \mathrm{g}^{-1}\right)$.

The selectivity is the important evaluation criteria to efficient separation of $\alpha$-tocopherol from tocopherol homologues. As displayed in Fig. 4b, HIPs have excellent separation performance for tocopherol homologues. The best-performing HIP[BzMIm] $\left[\mathrm{C}_{5} \mathrm{H}_{11} \mathrm{COO}\right]$ possesses high selectivity of $\beta \& \gamma$-tocopherol to $\alpha$-tocopherol $\left(S_{\beta \& \gamma / \alpha}\right)$ reaching 4.26 and the selectivity of $\delta$-tocopherol to $\alpha$-tocopherol $\left(S_{\delta / \alpha}\right)$ up to 3.19. In distinct contrast, HCP without ILs has a low selectivity with only 1.63 and 1.08 for $S_{\beta \& \gamma / \alpha}$ and $S_{\delta / \alpha}$, respectively. That is, tocopherol homologues possess highly similar structures but subtle difference in acidity, and for carboxylate-based HIPs, the efficient separation of $\alpha$-tocopherol arises from the introduction of adequate carboxylate ILs featuring the unique recognition for $\alpha$ tocopherol with the lowest acidity among tocopherol homologues [37,51-54]. Although the two commercial resins have good tocopherol adsorption capacity, their $S_{\beta \& \gamma / \alpha}$ and $S_{\delta / \alpha}$ values are only close to 1 , which means that they are unable to recognize the subtle difference of acidity among tocopherol homologues.

Anion-functionalized ILs contribute to highly efficient separation performance. Considering that HIP-[BzMIm] $\left[\mathrm{C}_{5} \mathrm{H}_{11^{-}}\right.$ COO] exhibits the best separation selectivity for tocopherol homologues, HIP-[BzMIm] $\left[\mathrm{C}_{5} \mathrm{H}_{11} \mathrm{COO}\right]$, prepared by the reaction of [BzMIm] $\left[\mathrm{C}_{5} \mathrm{H}_{11} \mathrm{COO}\right]$ with DBX at ratios of 1:4 and 1:1, was also put into the batch experiments. As presented in Fig. 4c, HIP-[BzMIm] $\left[\mathrm{C}_{5} \mathrm{H}_{11} \mathrm{COO}\right]$ (1:4) with a low IL content $\left(0.40 \mathrm{mmol} \mathrm{g}^{-1}\right)$ but the largest $S_{\mathrm{BET}}\left(855 \mathrm{~m}^{2} \mathrm{~g}^{-1}\right)$ and $V_{\text {total }}$ $\left(1.151 \mathrm{~cm}^{3} \mathrm{~g}^{-1}\right)$ possesses the highest adsorption capacity $\left(175.6 \mathrm{mg} \mathrm{g}^{-1}\right)$. That is, adsorption performance of tocopherols is cooperatively affected by porosity and functional sites. Besides, HIP-[BzMIm] [C $\left.{ }_{5} \mathrm{H}_{11} \mathrm{COO}\right](1: 1)\left(S_{\text {BET }}: 65 \mathrm{~m}^{2} \mathrm{~g}^{-1}\right)$, a nearly nonporous material with the highest IL content $\left(1.02 \mathrm{mmol} \mathrm{g}^{-1}\right)$, also exhibits a high adsorption capacity $\left(140.4 \mathrm{mg} \mathrm{g}^{-1}\right)$. The possible explanation is that the high content of strongly basic carboxylate IL moiety in the polymers will lead to high capacity benefiting from the strong hydrogen-bonding interaction with the acid tocopherols; meanwhile, the swelling behavior could also make for adsorption. And all the three samples exhibit high selectivity. In conclusion, rational choice for the ratio of IL and
$\mathrm{DBX}$ is the key to achieve high-performance adsorptive separation. In addition, $\mathrm{HIP}-[\mathrm{BzMIm}]\left[\mathrm{C}_{5} \mathrm{H}_{11} \mathrm{COO}\right]$ shows excellent recycling performance. After five recycling tests, the adsorption capacity almost remains unchanged (Fig. 4d). Besides, the batch adsorption experiment with $2.3 \mathrm{~g}$ of HIP[BzMIm] $\left[\mathrm{C}_{5} \mathrm{H}_{11} \mathrm{COO}\right]$ was conducted to evaluate the practical separation ability. The results shown in Table S1 prove that HIPs achieve the efficient separation and concentration of tocopherol homologues. After adsorption equilibrium, $\alpha$-tocopherol is concentrated in the liquid phase, and the percentage is obviously improved from $41.84 \%$ to $68.44 \%$; meanwhile, $\beta-/ \gamma$-tocopherol and $\delta$-tocopherol are concentrated in the adsorbent. Moreover, the regeneration and collection are achieved by conducting elution with ethanol.

Moreover, FTIR and solid state ${ }^{13} \mathrm{C}$ NMR spectra were also collected after adsorption. As depicted in Fig. S8, after adsorption, HIP-[BzMIm] $\left[\mathrm{C}_{5} \mathrm{H}_{11} \mathrm{COO}\right]$ presents the similar structure with the pristine sample, indicating well-preserved structural integrity during the batch experiments. The new peaks at 2924 and $2867 \mathrm{~cm}^{-1}$ in FTIR results as well as the peaks at $21 \mathrm{ppm}$ in the solid state ${ }^{13} \mathrm{C}$ NMR spectrum belong to the adsorbed tocopherols. To further confirm the effect of hydrogen-bonding interaction, a control experiment was carried out. After the addition of $2 \mathrm{wt} \%$ acetic acid into the separation systems, the tocopherol adsorption capacity for HIP-[BzMIm] $\left[\mathrm{C}_{5} \mathrm{H}_{11} \mathrm{COO}\right]$ decreases from 103.6 to $25.2 \mathrm{mg} \mathrm{g}^{-1}, S_{\beta \& \gamma / \alpha}$ and $S_{\delta / \alpha}$ also decrease from 4.26 and 3.19 to 1.30 and 1.13 , respectively. These results clarify that the extra hydrogen-bonding donor acetic acid can destroy the hydrogen bonds between HIPs and tocopherols, leading to reduced performance.

\section{Selective separation of organic phenolic compounds}

Phenol, $p$-cresol and 2,6-dimethylphenol with highly similar structures but difference in hydrogen-bonding acidity (Fig. S7) are important raw materials for pharmaceutical intermediates, and the efficient separation of these phenolic compounds is significant but still difficult.

As depicted in Fig. 5, HIPs have remarkably higher adsorption capacity of phenolic compounds than that of HCP. The adsorption capacity in HIP-[BzMIm] $\left[\mathrm{C}_{5} \mathrm{H}_{11} \mathrm{COO}\right]$ is $264.0 \mathrm{mg} \mathrm{g}^{-1}$, which is 2.9 times that of $\mathrm{HCP}\left(91.2 \mathrm{mg} \mathrm{g}^{-1}\right)$. And these carboxylate-based HIPs possess higher capacities (230.5-264.0 $\left.\mathrm{mg} \mathrm{g}^{-1}\right)$ than HIP-[BzMIm][Br] $\left(195.8 \mathrm{mg} \mathrm{g}^{-1}\right)$. The selectivities of phenol to 2,6-dimethylphenol $\left(S_{\text {phenol/2,6-dim }}\right)$
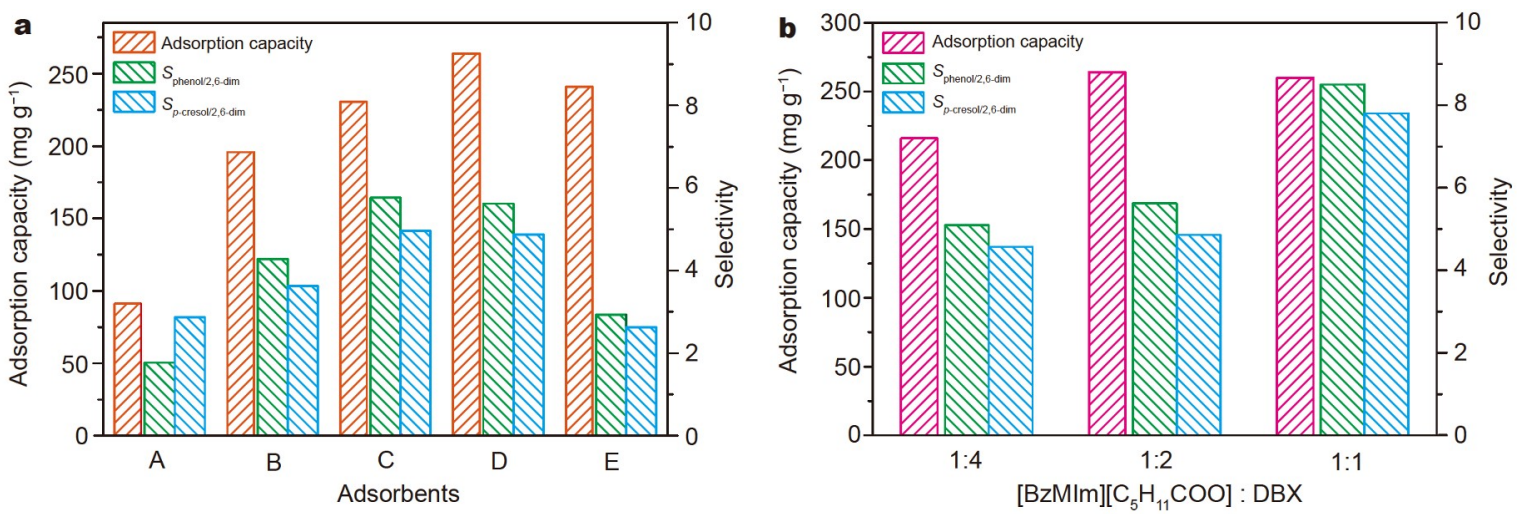

Figure 5 Adsorption capacity and selectivity of phenolic compounds by different adsorbents (a) and HIP-[BzMIm] [C $\left.\mathrm{C}_{5} \mathrm{H}_{11} \mathrm{COO}\right]$ with different IL contents (b) at 298 K. Adsorbents: A, HCP; B, HIP-[BzMIm] [Br]; C, HIP-[BzMIm] $\left[\mathrm{CH}_{3} \mathrm{COO}\right.$; D, HIP-[BzMIm] $\left[\mathrm{C}_{5} \mathrm{H}_{11} \mathrm{COO}\right] ; \mathrm{E}, \mathrm{HIP}-[\mathrm{BzMIm}]\left[\mathrm{C}_{11} \mathrm{H}_{23} \mathrm{COO}\right]$. 
and $p$-cresol to 2,6-dimethylphenol $\left(S_{p \text {-cresol/2,6-dim }}\right)$ are 4.28 and 3.63 for HIP-[BzMIm] [Br], respectively, which obviously exceed those of HCP ( $S_{\text {phenol/2,6-dim }}: 1.77, S_{p \text {-cresol/2,6-dim: }}$ 2.87). When the common anion $[\mathrm{Br}]^{-}$is replaced by $\left[\mathrm{C}_{5} \mathrm{H}_{11} \mathrm{COO}\right]^{-}, S_{p \text {-cresol/2,6-dim }}$ and $S_{\text {phenol/2,6-dim }}$ are further improved in HIP-[BzMIm] $\left[\mathrm{C}_{5} \mathrm{H}_{11^{-}}\right.$ COO], which reach 5.62 and 4.87 , respectively. Therefore, the inclusion of adequate functional anions is the efficient strategy to achieve high-performance separation. Besides, the content of ILs can also affect the separation performance of phenolic compounds (Fig. 5b). The increased IL content gives rise to enhanced selectivity with high capacity.

\section{CONCLUSIONS}

In summary, we have demonstrated an easy and straightforward route for the preparation of anion-functionalized HIPs. Carboxylate ILs have been successfully introduced into the hypercrosslinked framework via direct Friedel-Crafts alkylation between the benzylimidazole ILs and crosslinkers. These anionfunctionalized HIPs exhibit abundant meso-microporosity and adequate IL moieties. The tubular morphology and excellent thermal stability make HIPs more useful for practical application. High adsorption capacity (103.6 $\mathrm{mg} \mathrm{g}^{-1}$ for tocopherols) and excellent selectivity $\left(S_{\beta \& \gamma / \alpha}, 4.26 ; S_{\delta / \alpha}, 3.19\right)$ for tocopherol homologues with highly similar structures have been realized by anion-functionalized HIPs, in comparison to commercial adsorbents, HCP without ILs and HIPs with common ILs. Good reusability is demonstrated by the recycling tests of adsorption for tocopherol homologues. High-performance adsorptive separation has also been accomplished for phenolic compounds. Well-developed pore structures collaborated with strongly basic ILs promote excellent adsorptive separation with unique molecular recognition for important organic compounds. This work can inspire the design of new porous ionic materials for advanced separation via the rational molecular design and the inclusion of functional sites.

\section{Received 17 June 2021; accepted 27 October 2021; published online 29 November 2021}

1 Zhang Y, Riduan SN. Functional porous organic polymers for heterogeneous catalysis. Chem Soc Rev, 2012, 41: 2083-2094

2 Zou L, Sun Y, Che S, et al. Porous organic polymers for post-combustion carbon capture. Adv Mater, 2017, 29: 1700229

3 Wang W, Zhou M, Yuan D. Carbon dioxide capture in amorphous porous organic polymers. J Mater Chem A, 2017, 5: 1334-1347

4 Dawson R, Stöckel E, Holst JR, et al. Microporous organic polymers for carbon dioxide capture. Energy Environ Sci, 2011, 4: 4239-4245

5 Trewin A, Cooper AI. Porous organic polymers: Distinction from disorder? Angew Chem Int Ed, 2010, 49: 1533-1535

6 Zhang SY, Zhuang Q, Zhang M, et al. Poly(ionic liquid) composites. Chem Soc Rev, 2020, 49: 1726-1755

7 Van Humbeck JF, McDonald TM, Jing X, et al. Ammonia capture in porous organic polymers densely functionalized with Brønsted acid groups. J Am Chem Soc, 2014, 136: 2432-2440

8 Suo X, Cui X, Yang L, et al. Synthesis of ionic ultramicroporous polymers for selective separation of acetylene from ethylene. Adv Mater, 2020, 32: 1907601

9 Suo X, Yu Y, Qian S, et al. Tailoring the pore size and chemistry of ionic ultramicroporous polymers for trace sulfur dioxide capture with high capacity and selectivity. Angew Chem Int Ed, 2021, 60: 6986-6991

10 Cui X, Chen K, Xing H, et al. Pore chemistry and size control in hybrid porous materials for acetylene capture from ethylene. Science, 2016, 353: $141-144$

11 Xie Y, Lin J, Liang J, et al. Hypercrosslinked mesoporous poly(ionic liquid)s with high density of ion pairs: Efficient adsorbents for $\mathrm{Cr}(\mathrm{VI})$ removal via ion-exchange. Chem Eng J, 2019, 378: 122107

12 Bara JE, Carlisle TK, Gabriel CJ, et al. Guide to $\mathrm{CO}_{2}$ separations in imidazolium-based room-temperature ionic liquids. Ind Eng Chem Res, 2009, 48: 2739-2751

13 Bara JE, Gabriel CJ, Carlisle TK, et al. Gas separations in fluoroalkylfunctionalized room-temperature ionic liquids using supported liquid membranes. Chem Eng J, 2009, 147: 43-50

14 Sun JK, Antonietti M, Yuan J. Nanoporous ionic organic networks: From synthesis to materials applications. Chem Soc Rev, 2016, 45: 6627-6656

15 Zhang S, Dokko K, Watanabe M. Porous ionic liquids: Synthesis and application. Chem Sci, 2015, 6: 3684-3691

16 Zhang P, Qiao ZA, Jiang X, et al. Nanoporous ionic organic networks: Stabilizing and supporting gold nanoparticles for catalysis. Nano Lett, 2015, 15: 823-828

17 Zhang P, Li M, Yang B, et al. Polymerized ionic networks with high charge density: Quasi-solid electrolytes in lithium-metal batteries. Adv Mater, 2015, 27: 8088-8094

18 Wang J, Sng W, Yi G, et al. Imidazolium salt-modified porous hypercrosslinked polymers for synergistic $\mathrm{CO}_{2}$ capture and conversion. Chem Commun, 2015, 51: 12076-12079

19 Wilke A, Yuan J, Antonietti M, et al. Enhanced carbon dioxide adsorption by a mesoporous poly(ionic liquid). ACS Macro Lett, 2012, 1: 1028-1031

20 Gao C, Chen G, Wang X, et al. A hierarchical meso-macroporous poly(ionic liquid) monolith derived from a single soft template. Chem Commun, 2015, 51: 4969-4972

21 Zhao Q, Zhang P, Antonietti M, et al. Poly(ionic liquid) complex with spontaneous micro-/mesoporosity: Template-free synthesis and application as catalyst support. J Am Chem Soc, 2012, 134: 11852-11855

22 Lee JSM, Briggs ME, Hasell T, et al. Hyperporous carbons from hypercrosslinked polymers. Adv Mater, 2016, 28: 9804-9810

23 Dawson R, Stevens LA, Drage TC, et al. Impact of water coadsorption for carbon dioxide capture in microporous polymer sorbents. J Am Chem Soc, 2012, 134: 10741-10744

24 Woodward RT, Stevens LA, Dawson R, et al. Swellable, water- and acidtolerant polymer sponges for chemoselective carbon dioxide capture. J Am Chem Soc, 2014, 136: 9028-9035

25 Luo Y, Li B, Wang W, et al. Hypercrosslinked aromatic heterocyclic microporous polymers: A new class of highly selective $\mathrm{CO}_{2}$ capturing materials. Adv Mater, 2012, 24: 5703-5707

26 Yang Y, Tan B, Wood CD. Solution-processable hypercrosslinked polymers by low cost strategies: A promising platform for gas storage and separation. J Mater Chem A, 2016, 4: 15072-15080

27 Li J, Jia D, Guo Z, et al. Imidazolinium based porous hypercrosslinked ionic polymers for efficient $\mathrm{CO}_{2}$ capture and fixation with epoxides. Green Chem, 2017, 19: 2675-2686

28 Wang J, Wei Yang JG, Yi G, et al. Phosphonium salt incorporated hypercrosslinked porous polymers for $\mathrm{CO}_{2}$ capture and conversion. Chem Commun, 2015, 51: 15708-15711

29 Shen R, Yan X, Guan YJ, et al. One-pot synthesis of a highly porous anionic hypercrosslinked polymer for ultrafast adsorption of organic pollutants. Polym Chem, 2018, 9: 4724-4732

30 Zhang W, Ma F, Ma L, et al. Imidazolium-functionalized ionic hypercrosslinked porous polymers for efficient synthesis of cyclic carbonates from simulated flue gas. ChemSusChem, 2020, 13: 341-350

31 Sang Y, Huang J. Benzimidazole-based hyper-cross-linked poly(ionic liquid)s for efficient $\mathrm{CO}_{2}$ capture and conversion. Chem Eng J, 2020, 385: 123973

32 Yang Q, Zhang Z, Sun XG, et al. Ionic liquids and derived materials for lithium and sodium batteries. Chem Soc Rev, 2018, 47: 2020-2064

33 Suo X, Xia L, Yang Q, et al. Synthesis of anion-functionalized mesoporous poly(ionic liquid)s via a microphase separation-hypercrosslinking strategy: Highly efficient adsorbents for bioactive molecules. J Mater Chem A, 2017, 5: 14114-14123

34 Xie Y, Xing H, Yang Q, et al. Aqueous biphasic system containing long chain anion-functionalized ionic liquids for high-performance extraction. ACS Sustain Chem Eng, 2015, 3: 3365-3372

35 Jin W, Yang Q, Zhang Z, et al. Self-assembly induced solubilization of 
drug-like molecules in nanostructured ionic liquids. Chem Commun, 2015, 51: 13170-13173

36 Yang Q, Xu D, Zhang J, et al. Long-chain fatty acid-based phosphonium ionic liquids with strong hydrogen-bond basicity and good lipophilicity: Synthesis, characterization, and application in extraction. ACS Sustain Chem Eng, 2014, 3: 309-316

37 Liu X, Yang Q, Bao Z, et al. Nonaqueous lyotropic ionic liquid crystals: Preparation, characterization, and application in extraction. Chem Eur J, 2015, 21: 9150-9156

38 Modak A, Bhaumik A. High-throughput acid-base tandem organocatalysis over hollow tube-shaped porous polymers and carbons. ChemistrySelect, 2016, 1: 1192-1200

39 Wang X, Mu P, Zhang C, et al. Control synthesis of tubular hypercross-linked polymers for highly porous carbon nanotubes. ACS Appl Mater Interfaces, 2017, 9: 20779-20786

40 Yang Z, Liu Z, Zhang H, et al. N-doped porous carbon nanotubes: Synthesis and application in catalysis. Chem Commun, 2017, 53: 929 932

41 Cho HC, Lee HS, Chun J, et al. Tubular microporous organic networks bearing imidazolium salts and their catalytic $\mathrm{CO}_{2}$ conversion to cyclic carbonates. Chem Commun, 2011, 47: 917-919

42 Packer L. Protective role of vitamin E in biological systems. Am J Clin Nutr, 1991, 53: 1050S-1055S

43 Azzi A, Stocker A. Vitamin E: Non-antioxidant roles. Prog Lipid Res, 2000, 39: 231-255

44 Hosomi A, Arita M, Sato Y, et al. Affinity for $\alpha$-tocopherol transfer protein as a determinant of the biological activities of vitamin $\mathrm{E}$ analogs. FEBS Lett, 1997, 409: 105-108

45 Yu G, Lu Y, Liu X, et al. Polyethylenimine-assisted extraction of $\alpha$ tocopherol from tocopherol homologues and $\mathrm{CO}_{2}$-triggered fast recovery of the extractant. Ind Eng Chem Res, 2014, 53: 16025-16032

$46 \mathrm{Lu} \mathrm{Y,} \mathrm{Yu} \mathrm{G,} \mathrm{Wang} \mathrm{WJ,} \mathrm{et} \mathrm{al.} \mathrm{Design} \mathrm{and} \mathrm{synthesis} \mathrm{of} \mathrm{thermoresponsive}$ ionic liquid polymer in acetonitrile as a reusable extractant for separation of tocopherol homologues. Macromolecules, 2015, 48: 915924

47 Qin L, Zhang J, Cheng H, et al. Selection of imidazolium-based ionic liquids for vitamin $\mathrm{E}$ extraction from deodorizer distillate. ACS Sustain Chem Eng, 2016, 4: 583-590

48 Mohammadi B, Shekaari H, Zafarani-Moattar MT. Selective separation of $\alpha$-tocopherol using eco-friendly choline chloride-based deep eutectic solvents (DESs) via liquid-liquid extraction. Colloids Surfs A-Physicochem Eng Aspects, 2021, 617: 126317

49 Qin L, Li J, Cheng H, et al. Association extraction for vitamin E recovery from deodorizer distillate by in situ formation of deep eutectic solvent. AIChE J, 2017, 63: 2212-2220

50 Liu X, Ji C, Yang Q, et al. Carboxylate ionic liquids combining low cytotoxicity toward HepG2 cell and high separation efficiency for bioactive molecules. ACS Sustain Chem Eng, 2017, 5: 1974-1981

$51 \mathrm{Ni} \mathrm{X}$, Xing $\mathrm{H}$, Yang $\mathrm{Q}$, et al. Selective liquid-liquid extraction of natural phenolic compounds using amino acid ionic liquids: A case of $\alpha$-tocopherol and methyl linoleate separation. Ind Eng Chem Res, 2012, 51: 6480-6488

52 Yang Q, Xing H, Cao Y, et al. Selective separation of tocopherol homologues by liquid-liquid extraction using ionic liquids. Ind Eng Chem Res, 2009, 48: 6417-6422

53 Yang Q, Xing H, Su B, et al. The essential role of hydrogen-bonding interaction in the extractive separation of phenolic compounds by ionic liquid. AIChE J, 2013, 59: 1657-1667

54 Xu D, Yang Q, Su B, et al. Enhancing the basicity of ionic liquids by tuning the cation-anion interaction strength and via the anion-tethered strategy. J Phys Chem B, 2014, 118: 1071-1079

Acknowledgements This work was financially supported by the National Natural Science Foundation of China (21908191, 21938011 and 21890764), Zhejiang Provincial Natural Science Foundation of China (LR20B060001), and the Entrepreneur Team Introduction Program of Zhejiang (2019R01006).
Author contributions Xing $\mathrm{H}$, Suo $\mathrm{X}$ and Huang $\mathrm{Y}$ proposed the idea; Suo $\mathrm{X}$ and Huang $\mathrm{Y}$ designed the samples and performed the experiments; Li $\mathrm{Z}$ and Pan $\mathrm{H}$ did the measurements; Suo X and Huang Y wrote the paper with support from Xing $\mathrm{H}$ and Cui X. All authors contributed to the general discussion.

Conflict of interest The authors declare that they have no conflict of interest.

Supplementary information Experimental details and supporting data are available in the online version of the paper.

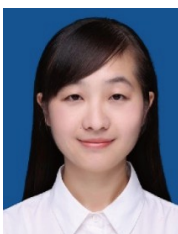

Xian Suo received her $\mathrm{PhD}$ degree in chemical engineering and technology from Zhejiang University in 2018. She was a postdoctoral fellow at Zhejiang University from 2018 to 2020 , focusing on the design and synthesis of ultramicroporous materials for adsorptive separation. In the meanwhile, she has been working as a postdoctoral researcher in Prof. Sheng Dai's group at the University of Tennessee, Knoxville (UTK) since 2019. She focuses on the development of functional ionic materials and their applications in advanced separation.

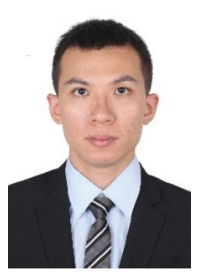

Yuqi Huang obtained his master's degree in pharmaceutical engineering at the College of Chemical and Biological Engineering, Zhejiang University in 2019. His research interests focus on the design and synthesis of anionfunctionalized materials for the separation of hydrocarbons and natural active compounds.

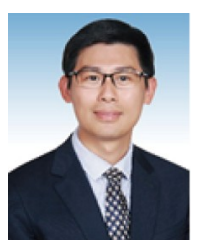

Huabin Xing received his BSc degree in pharmaceutical engineering (2000) and MSc degree in chemical engineering (2003) from Zhejiang University, and a PhD degree in chemical engineering (2007) from Tsinghua University. Then he joined the College of Chemical and Biological Engineering, Zhejiang University, in 2007 as a postdoctoral fellow. He became a full professor in 2014 and currently serves as a Qiushi Distinguished Professor and dean of College of Chemical and Biological Engineering at Zhejiang University. His research interests focus on the preparation of functional materials for separation and energy storage. He has published over 150 journal articles, and was selected as the National Natural Science Foundation of China (NSFC) Distinguished Young Scholar and ACS I\&EC 2017/2018 Class of Influential Researcher

\section{阴离子功能化超交联离子多孔聚合物的构建及生物 活性物质高效分离}

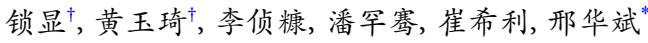

摘要 多孔离子聚合物由于其独特的分子识别能力在高效分离中表现 出巨大的潜力, 但制备阴离子功能化离子聚合物用于结构高度相似生 物活性物质分离仍然具有挑战. 本文通过苄基咪唑离子液体与交联剂 发生简易的Friedel-Crafts烷基化反应，报道了一类具有强碱羧酸阴离 子功能化、管状形貌和高热稳定性的超交联离子多孔聚合物(HIPs). 实现了对结构高度相似的生物活性化合物的高容量(生育酚同系物: $\left.103.6 \mathrm{mg} \mathrm{g}^{-1}\right)$ 和高选择性 $\left(S_{\beta \& \gamma / \alpha}, 4.26 ; S_{\delta / \alpha}, 3.19\right)$ 吸附分离, 其性能优于 商业吸附剂、不含离子液体的超交联聚合物和含常规离子液体的 HIPs. 本研究展示了功能化吸附剂新的合成策略和合理的分子设计, 为 实现高效分离提供了新的机会. 